\author{
О. Г. Рудак, А. Ю. Короб
}

Белорусский государственный технологический университет

\title{
ИССЛЕДОВАНИЕ ХАРАКТЕРА ИЗМЕНЕНИЯ ВЛАЖНОСТИ ПОВЕРХНОСТНЫХ И ВНУТРЕННИХ СЛОЕВ ДРЕВЕСИНЫ СОСНЫ ПРИ ПРОГРЕВЕ В НЕНАСЫЩЕННОЙ СРЕДЕ
}

В статье приведены результаты исследования механизма перемещения влаги в древесине в период прогрева в ненасыщенной среде. Получены зависимости, отражающие характер изменения влажности на поверхности и внутри древесины во времени. Определены закономерности изменения величины перепада влажности образцов, имеющих различные параметры от степени насыщенности и температуры обрабатывающей среды во времени. В данной работе обращается внимание на то, что в период прогрева древесины наблюдается заметный перепад влажности на поверхности и внутри образца, что является причиной неравномерного распределения влаги по толщине пиломатериала.

В свою очередь, возникновение разницы влажности между поверхностными и внутренними слоями древесины является причиной перемещения влаги по направлению от более влажных центральных к менее влажным поверхностным слоям. Полученные экспериментальные данные свидетельствуют, что на характер изменения влажности древесины в период прогрева влияние оказывают следующие переменные факторы: температура прогрева, степень насыщенности обрабатывающей среды, начальная влажность образца, толщина образцов.

Результаты исследований могут быть использованы при разработке режимов начального прогрева, повышающих качество продукции и снижающих энергозатраты на проведение данного процесса.

Ключевые слова: прогрев, режим, перепад влажности, градиент влажности, влагопроводность.

Для цитирования: Рудак О. Г., Короб А. Ю. Исследование характера изменения влажности поверхностных и внутренних слоев древесины сосны при прогреве в ненасыщенной среде // Труды БГТУ. Сер. 1, Лесное хоз-во, природопользование и перераб. возобновляемых ресурсов. 2021. № 1 (240). C. 162-168.

\section{O. G. Rudak, A. Yu. Korob \\ Belarusian State Technological University \\ STUDY OF THE CHARACTER OF MOISTURE CHANGE IN SURFACE AND INNER LAYERS OF PINE WOOD DURING HEATING IN A UNSATURATED ENVIRONMENT}

The article presents the results of research on the mechanism of movement of moisture in wood during heating in an unsaturated environment. Dependences are obtained that reflect the nature of changes in humidity on the surface and inside the wood over time. The regularities of changes in the value of the humidity drop of samples with different parameters from the degree of saturation and temperature of the processing medium over time are determined. In this work, attention is drawn to the fact that during the heating period of wood, there is a noticeable difference in humidity on the surface and inside the sample, which is the reason for the uneven distribution of moisture over the thickness of the lumber.

In turn, the occurrence of a difference in humidity between the surface and inner layers of wood causes moisture to move in the direction from the more humid Central to the less humid surface layers. The experimental data obtained indicate that the nature of changes in the moisture content of wood during the heating period is influenced by the following variables: the heating temperature, the degree of saturation of the processing medium, the initial humidity of the sample, and the thickness of the samples.

The results of the research can be used in the development of modes of initial heating, which improve the quality of products and reduce energy consumption for this process.

Key words: initial heating, mode, moisture difference, the gradient of humidity, moisture conductivity.

For citation: Rudak O. G., Korob A. Yu. Study of the character of moisture change in surface and inner layers of pine wood during heating in a unsaturated environment. Proceedings of BSTU, issue 1, Forestry. Nature Management. Processing of Renewable Resources, 2021, no. 1 (240), pp. 162-168 (In Russian). 
Введение. На сегодняшний день в Республике Беларусь производится около 2 млн м ${ }^{3}$ пиломатериалов в год, большая часть из которых подвергается камерной сушке. Породный состав производимых пиломатериалов представляет собой следующее соотношение: $67 \%$ древесины хвойных пород (в основном сосна) и $33 \%$ древесины лиственных пород.

Начальный прогрев древесины в камере производят перед собственно сушкой для предупреждения образования впоследствии внутренних напряжений, а также для сохранения целостности пиломатериалов в начальный период процесса.

Эффективным путем снижения энергозатрат при сушке древесины является проведение операции начального прогрева в ненасыщенной среде, который сопровождается изменениями ее (среды) влажности.

Целью настоящей работы являлись исследования процессов и характера изменения влажности поверхностных и внутренних слоев древесины во времени при различных условиях обрабатывающей среды.

Основная часть. В соответствии с общепринятой практикой и Руководящими техническими материалами по технологии камерной сушки древесины [1], для безопасного начального прогрева перед сушкой в камере создается высокая степень насыщенности среды при повышенной, по сравнению с первой ступенью режима сушки, температуре. Для создания высокой степени насыщенности психрометрическую разность поддерживают на уровне $0,5-1,5^{\circ} \mathrm{C}(\varphi=$ $=0,93-0,97)$. Однако в современной литературе [2] степень насыщенности среды при прогреве в камерах с теплоносителем и увлажнителем водяной пар предлагают устанавливать иначе: для древесины с начальной влажностью более $25 \%$ - в пределах 0,98-1,00 а для древесины с влажностью менее $25 \%-0,90-0,92$. В таких условиях испарение влаги с поверхностных слоев древесины незначительно и не влияет на общее распределение влажности по толщине пиломатериала.

Также стоит отметить, что современные технологии сушки предполагают использование режимов начального прогрева, при которых степень насыщенности обрабатывающей среды $\varphi<1$, разница показаний психрометра $\Delta t$ не превышает $5^{\circ} \mathrm{C}$, а температура прогрева устанавливается на уровне, не превышающем температуру сушки на первой ступени режима сушки. Как правило, это не более $70^{\circ} \mathrm{C}$. При таких условиях интенсивность испарения влаги с поверхности пиломатериалов и перемещение ее из внутренних более влажных слоев к наружным значительно ниже, чем в процессе непосредственно сушки пиломатериалов.
При проведении начального прогрева обязательными контролируемыми параметрами обрабатывающего агента являются [3, 4]:

1) температура $T,{ }^{\circ} \mathrm{C}$;

2) степень насыщенности $\varphi$;

3) психрометрическая разность $\Delta t,{ }^{\circ} \mathrm{C}$.

Непосредственно для самих пиломатериалов основными параметрами являются порода древесины, начальная влажность и температура, толщина [5-7].

Обращает на себя внимание тот факт, что в современных сушильных камерах взаимосвязь между температурой, степенью насыщенности обрабатывающего агента и начальной влажностью пиломатериала отображают как значение равновесной влажности, которая на экране пульта управления обозначается английскими буквами EMC. Количественные значения параметров режима прогрева каждая фирма-производитель устанавливает согласно своим требованиям. Сушильное хозяйство Республики Беларусь в большинстве своем состоит из камер иностранного производства, соответственно и технология прогрева разная. Стоит также учитывать, что география стран-производителей сушильного оборудования и камер достаточно широкая, и данные для составления режимов могут существенно разниться. Например, камеры итальянского производства принимают за базисную плотность сосны $\rho=320 \kappa \Gamma / \mathrm{M}^{3}$, а у камер из стран Скандинавии около $480 \mathrm{\kappa г} / \mathrm{M}^{3} ;$ для нашего климата $\rho=400 \mathrm{\kappa r} / \mathrm{M}^{3}$. Также средняя начальная влажность и температура прогреваемых пиломатериалов существенно отличаются в южных и северных широтах. Соответственно, параметры режимов прогрева, его продолжительность не всегда могут быть эффективно применены для наших условий. Режимы начального прогрева древесины сосны для разных фирм-производителей отражены в табл. 1.

Таблица 1

Режимы начального прогрева

\begin{tabular}{|c|c|c|c|c|}
\hline \multirow{2}{*}{$\begin{array}{c}\text { Toлщина } \\
S, \text { мм }\end{array}$} & $\begin{array}{c}\text { Равновесная } \\
\text { влажность }\end{array}$ & \multicolumn{3}{|c|}{ Параметры режима } \\
\cline { 3 - 5 } & ЕМроге $\%$ & $\varphi$ & $\Delta t$ & $t,{ }^{\circ} \mathrm{C}$ \\
\hline \multicolumn{5}{|c|}{ Фирма SEKAL } \\
\hline $30-60$ & 14 & 0,77 & 4 & 40 \\
\hline$>60$ & 16 & 0,82 & 3 & 38 \\
\hline \multicolumn{5}{|c|}{ Фирма CATHILD } \\
\hline$<35$ & 14 & 0,81 & 4 & 65 \\
\hline $35-60$ & 14,5 & 0,83 & 3,5 & 65 \\
\hline \multicolumn{5}{|c|}{ Фирма HOK B HEIN } \\
\hline $36-75$ & 15,5 & 0,83 & 3,5 & 35 \\
\hline$>75$ & 15 & 0,81 & 3,5 & 35 \\
\hline \multicolumn{5}{|c|}{ Фирма INCOPLAN } \\
\hline $30-60$ & 18 & 0,86 & 2,5 & 45 \\
\hline$>60$ & 19 & 0,87 & 2 & 45 \\
\hline
\end{tabular}

Труды БГТУ Серия 1 № 12021 
Анализируя данные табл. 1, можно заметить, как отличается интервал параметров режима прогрева: одни производители проводят начальный прогрев в условиях близких к насыщению, а другие - при параметрах среды, соответствующих первой ступени сушки.

Измерение влажности в поверхностных и внутренних слоях опытных образцов в ходе эксперимента производили с помощью климатической камеры ТХВ, оснащенной датчиками влажности древесины, а также датчиками влажности и температуры обрабатывающего агента. В комплекте климаткамеры предусмотрены датчики влажности, позволяющие фиксировать ее изменение с точностью $\pm 1 \%$. Частота измерения - каждые 5 с. Все значения выводятся на экран контроля камеры.

Для определения температуры внутри древесины в период проведения эксперимента применяли оригинальную измерительную систему, имеющую восемь температурных датчиков модели DS18S20 с точностью измерения до 0,1 град. Частота измерения - каждые 5 с. Данная установка представляет собой автоматический измеритель температуры. Все значения выводятся на экран данного автоматического измерителя температур. Начальная влажность опытных образцов измерялась электровлагомером GANN HT 85.

В качестве экспериментального материала для исследования изменения влажности поверхностных и внутренних слоев древесины в процессе начального прогрева в ненасыщенной среде использовались сосновые образцы радиальной распиловки толщиной $S=20,40,60$ мм. Ширина пиломатериалов $b$ равнялась 250 мм, что существенно превосходит их толщину. Данный факт позволял считать, что перемещение влаги при прогреве происходило в основном в направлении, перпендикулярном пласти досок, т. е. от внутренних слоев к поверхностным.

На глубине, соответствующей половине толщины образца из древесины, располагаются датчик влажности $W_{1}$ и термодатчик $T_{1}$, а на поверхности древесины, соприкасающейся с агентом обработки, - датчик $W_{2}$ на глубине 34 мм (рис. 1). Все датчики были изолированы пастой КПТ-8 во избежание влияния обрабатывающего агента на результаты измерений. Начальная температура всех элементов системы была одинаковой и равной температуре окружающей среды $t_{0}==15-20^{\circ} \mathrm{C}$.

Экспериментальные образцы помещались в климатическую камеру, где производился их прогрев в ненасыщенной среде по установленному режиму. Прогрев проводили до тех пор, пока разница температур окружающей среды и внутренних слоев древесины не составляла $3^{\circ} \mathrm{C}$. Фиксируемыми параметрами в этом эксперименте являлись влажность поверхностных и внутренних слоев древесины, а также продолжительность прогрева.

Принципиальная схема проведения эксперимента представлена на рис. 1. Условия проведения экспериментальных исследований отражены в табл. 2 .

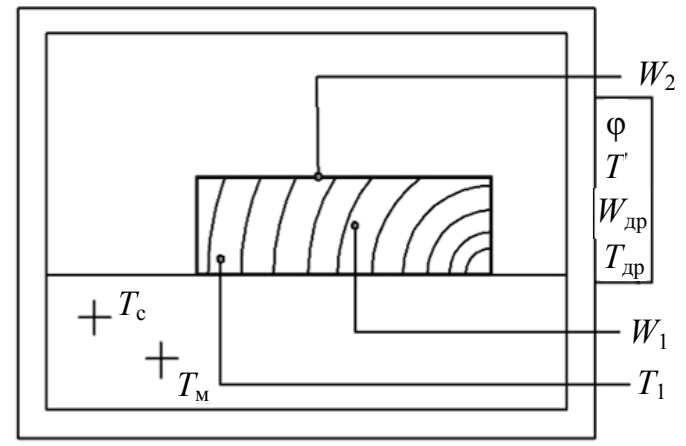

Рис. 1. Общий вид экспериментальной установки

Таблица 2

Условия проведения эксперимента

\begin{tabular}{|c|c|c|c|c|c|}
\hline \multicolumn{3}{|c|}{$\begin{array}{c}\text { Характеристика } \\
\text { образцов }\end{array}$} & \multicolumn{3}{|c|}{$\begin{array}{c}\text { Характеристика } \\
\text { обрабатывающего агента }\end{array}$} \\
\hline \multicolumn{2}{|c|}{$\begin{array}{c}\text { Размер } \\
\text { сечения, мм }\end{array}$} & \multirow{2}{*}{$W_{\text {нач }}, \%$} & \multirow[t]{2}{*}{$T,{ }^{\circ} \mathrm{C}$} & \multirow[t]{2}{*}{$\varphi$} & \multirow{2}{*}{$\begin{array}{c}W_{\mathrm{p}}, \% \\
\text { или ЕМС }\end{array}$} \\
\hline$S$ & $b$ & & & & \\
\hline \multirow{9}{*}{$20 / 40 / 60$} & \multirow{9}{*}{250} & \multirow{9}{*}{$>30 \%$} & \multirow{3}{*}{40} & 0,7 & 12 \\
\hline & & & & 0,8 & 15,5 \\
\hline & & & & 0,9 & 21 \\
\hline & & & \multirow{3}{*}{60} & 0,7 & 11 \\
\hline & & & & 0,8 & 14 \\
\hline & & & & 0,9 & 19 \\
\hline & & & \multirow{3}{*}{80} & 0,7 & 9,7 \\
\hline & & & & 0,8 & 12 \\
\hline & & & & 0,9 & 16 \\
\hline \multirow{9}{*}{$20 / 40 / 60$} & \multirow{9}{*}{250} & \multirow{9}{*}{$<30 \%$} & \multirow{3}{*}{40} & 0,7 & 12 \\
\hline & & & & 0,8 & 15,5 \\
\hline & & & & 0,9 & 21 \\
\hline & & & \multirow{3}{*}{60} & 0,7 & 11 \\
\hline & & & & 0,8 & 14 \\
\hline & & & & 0,9 & 19 \\
\hline & & & \multirow{3}{*}{80} & 0,7 & 9,7 \\
\hline & & & & 0,8 & 12 \\
\hline & & & & 0,9 & 16 \\
\hline
\end{tabular}

Результаты исследований по условиям табл. 2 представлены в виде графических зависимостей на рис. 2-6, а также в виде кинетических кривых. Поскольку характер изменения перепада влажности по толщине был одинаковым, то для анализа показаны зависимости при граничных условиях режима прогрева. 


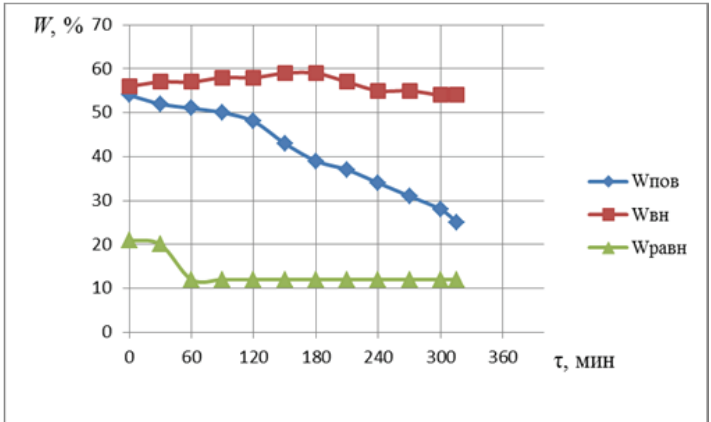

$a$

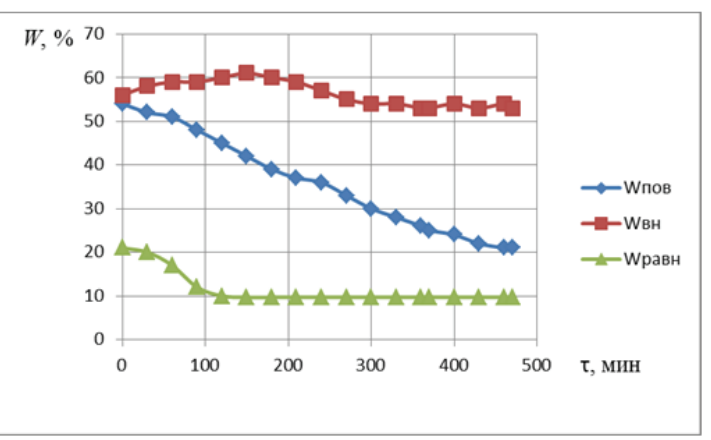

$\sigma$

Рис. 2. Изменение влажности древесины поверхностных и внутренних слоев при $W_{\text {нач }}=55 \%, \varphi=0,7, S=20$ мм: температура прогрева $40^{\circ} \mathrm{C}(a)$ и $80^{\circ} \mathrm{C}($ б $)$

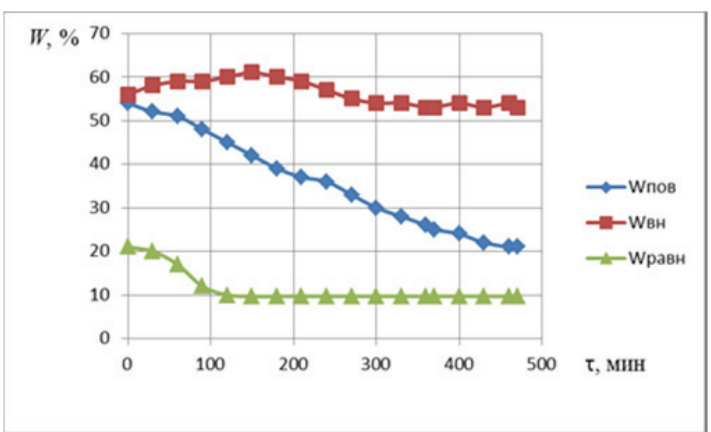

$a$

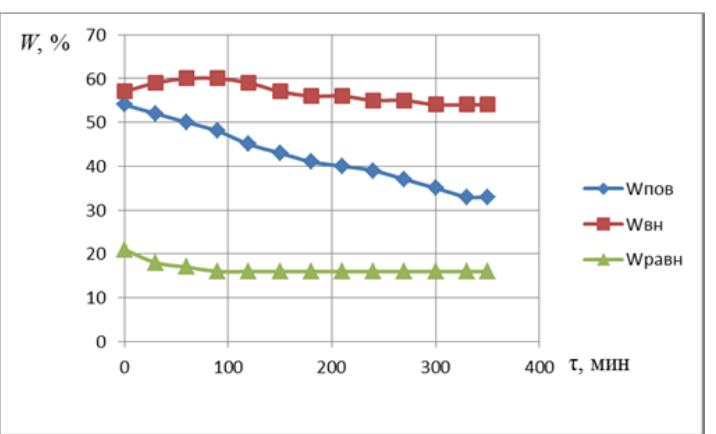

$\sigma$

Рис. 3. Изменение влажности древесины поверхностных и внутренних слоев при $W_{\text {нач }}=55 \%, T=80^{\circ} \mathrm{C}, S=20$ мм: степень насыщенности $\varphi=0,7$ (a) и 0,9 (б)

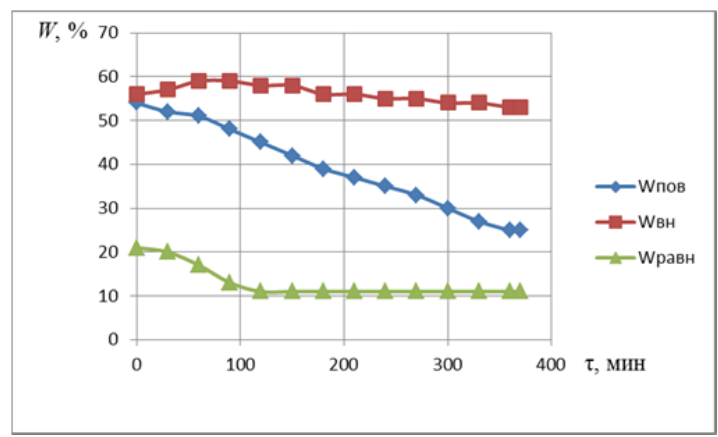

$a$

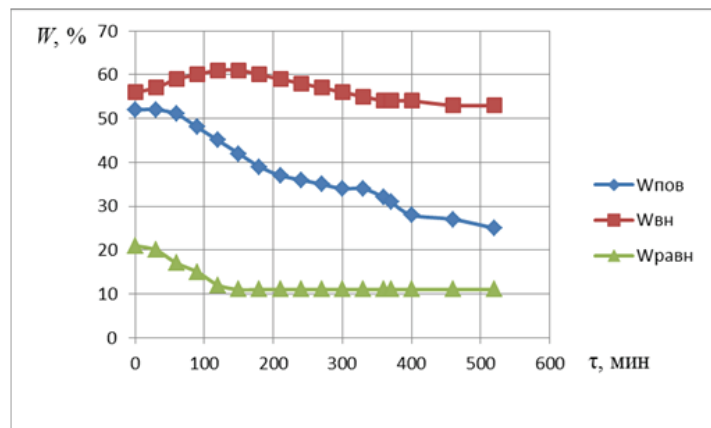

$\sigma$

Рис. 4. Изменение влажности древесины поверхностных и внутренних слоев при $W_{\text {нач }}=55 \%, T=60^{\circ} \mathrm{C}, \varphi=0,7:$ толщина образца $S=20(a)$ и 60 (б)

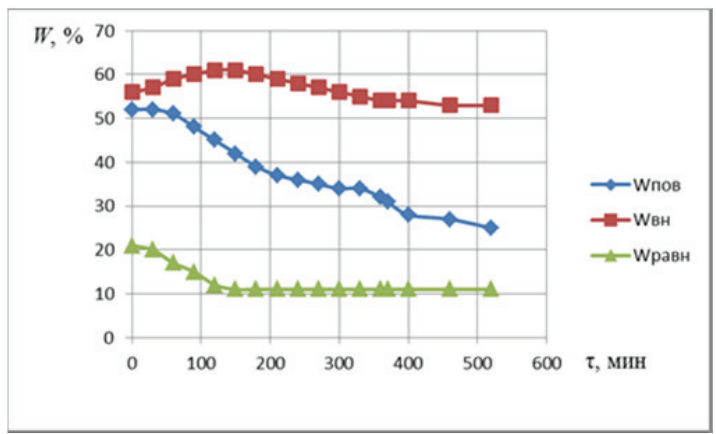

$a$

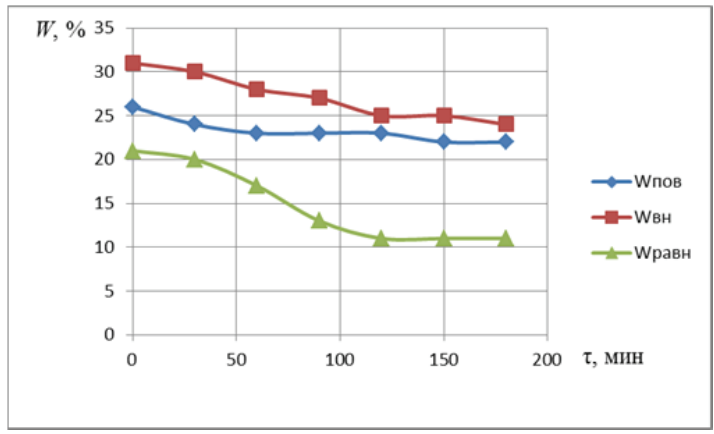

$\sigma$

Рис. 5. Изменение влажности древесины поверхностных и внутренних слоев при $T=60^{\circ} \mathrm{C}, \varphi=0,7$ мм, $S=20$ мм: $W_{\text {нач }}=55 \%(a)$ и $27 \%($ б) 


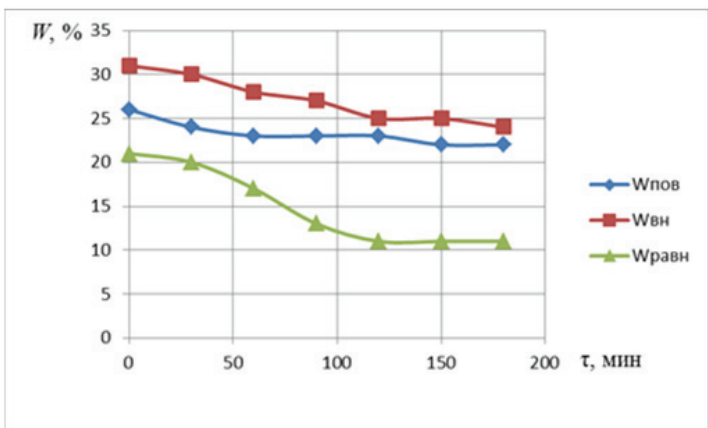

$a$

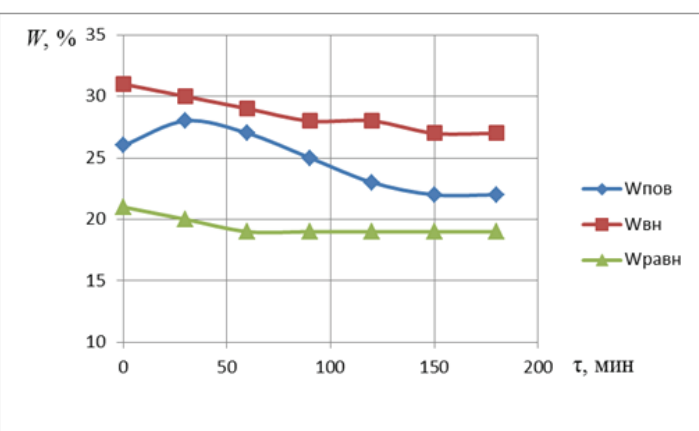

$\sigma$

Рис. 6. Изменение влажности древесины поверхностных и внутренних слоев при $T=60^{\circ} \mathrm{C}, W_{\text {нач }}=27 \%, S=20$ мм: $\varphi=0,7(a)$ и 0,9 (б)

Температура воздуха в климатической камере устанавливается на требуемом уровне $\left(40-80^{\circ} \mathrm{C}\right)$ уже через 3-10 мин после начала нагревания. После этого она остается неизменной на протяжении всего эксперимента. Таким образом, можно считать, что нагревание древесины проходит при постоянной температуре обрабатывающей среды.

Изменение влажности поверхностных слоев образцов древесины начинается через 30-60 мин после начала прогрева, а внутренних - с некоторым опозданием. Перепад влажности на поверхности и внутри образцов $\Delta W$ достигает максимальной величины к концу процесса прогрева.

Анализ полученных экспериментальных данных показал, что на характер изменения влажности поверхностных слоев древесины существенное влияние оказывает температура прогрева, степень насыщенности обрабатывающей среды, начальная влажность образцов. Толщина образцов оказывала влияние только на продолжительность процесса прогрева.

Стоит отметить, что влажность внутренних слоев увеличивается на 2-4\% именно в период, когда наблюдается достаточно интенсивное снижение влажности поверхностных слоев. Данное явление можно объяснить следующим образом. $\mathrm{B}$ период прогрева пиломатериалов под воздействием перепада температур возникает интенсивный поток влаги от более горячих зон к более холодным даже в тех случаях, когда холодная зона оказывается более влажной [8-10]. Влажность же поверхностных слоев с течением времени уменьшается, достигает значения, близкого к равновесной влажности, после чего не изменяется.

Нетрудно заметить, что стабилизация влажности на поверхности прогреваемых сортиментов происходит на уровне значения устойчивой влажности при десорбции, соответствующей заданным параметрам обрабатывающей среды. Перепад влажности по толщине пиломатериалов изменяется от 5-7\% в начале процесса до 24-29\% - в конце.
Следовательно, в образце возникает градиент влажности, под действием которого влага будет стремиться к перемещению в направлении, противоположном направлению потока влаги. Влага по объему сортимента всегда двигается в сторону убывающей влажности. При определенном соотношении между влажностным и температурным градиентами эффект влагопроводности полностью компенсирует эффект термовлагопроводности, и по сечению образца устанавливается стационарное поле температуры и влажности, что мы и наблюдаем в конце эксперимента.

Особый интерес представляет механизм прогрева при начальной влажности древесины $W_{\text {нач }}<30 \%$ (рис. 6). При степени насыщенности $\varphi=0,7$ и $T=60^{\circ} \mathrm{C}$ влажность как внутренних, так и поверхностных слоев снижается на протяжении всего процесса прогрева. Перепад влажности по толщине постепенно уменьшается к концу процесса, что свидетельствует об испарении влаги, т. е. о происходящем процессе сушки.

В случае же, когда $\varphi=0,9$ и $T=60^{\circ} \mathrm{C}$, поверхностные слои образца в начале процесса увлажняются, далее их влажность снижается и стремится к равновесной.

Также стоит отметить, что интенсивность изменения влажности поверхностных слоев древесины тем больше, чем больше разность $\Delta t$ между температурой обрабатывающей среды $T_{\mathrm{c}}$ и температурой в центральных слоях образцов $T_{1}$. Это можно объяснить положительным влиянием явления термовлагопроводности.

Оба случая, описанные выше, предполагают развитие внутренних напряжений в древесине уже на этапе начального прогрева, что, в свою очередь, является причиной возникновения дефектов сушки (трещины, коробления).

Сопоставление полученных графиков между собой позволило отметить следующее.

1. Процесс прогрева древесины в ненасыщенной среде характеризуется неравномерным распределением влаги по толщине пиломатериалов. 
2. С повышением температуры обрабатывающей среды увеличивается продолжительность процесса прогрева, а также возрастает скорость изменения влажности на поверхности древесины.

3. При увеличении начальной влажности древесины наблюдается разница в характере изменения кривых влажности поверхностных и внутренних слоев образца.

4. С увеличением толщины образца увеличивается продолжительность прогрева, а скорость изменения влажности поверхностных и внутренних слоев древесины остается практически одинаковой.

5. С увеличением степени насыщенности обрабатывающего агента продолжительность прогрева снижается за счет повышения теплосодержания влажного воздуха [11-13].

Дополнительное удаление влаги при прогреве и непосредственно на первой ступени сушки экономит расход диспергированной воды для создания требуемого параметра степени насыщенности обрабатывающей среды, причем чем выше температура прогрева, тем больше этот эффект. Также испаренная из пиломатериала влага изменит количество водяного пара в обрабатывающей среде на определенную величину [5].

Отметим также, что в результате прогрева древесины в ненасыщенной среде распределение влажности по толщине образцов носит параболический характер.

Полученные данные можно использовать при разработке режимов начального прогрева древесины в ненасыщенной среде. Для оптимальной подготовки влагопроводящей системы древесины к испарению влаги можно рекомендовать проводить прогрев древесины при температуре среды выше $50-60^{\circ} \mathrm{C}$ и $\varphi=0,75-0,85$ для пиломатериалов с начальной степенью влажности $W_{\text {нач }}>30 \%$.
Пиломатериалы с начальной влажностью $W_{\text {нач }}<30 \%$ рекомендуется прогревать в среде сушильного агента, степень насыщенности $\varphi$ которого по диаграмме равновесной влажности соответствуют начальной влажности материала.

Для пиломатериалов, предназначенных для отправки за границу, операция начального прогрева является одним из видов фитосанитарной обработки. Параметры режима должны быть следующие: $T=56^{\circ} \mathrm{C}, \varphi=0,7-0,8$, прогрев проводят до тех пор, пока по всей толщине материала не установится тепловое равновесие, и далее выдерживают в таких условиях полчаса и более.

Заключение. В период начального прогрева древесины наблюдается перепад влажности на поверхности и внутри образца. В свою очередь, возникновение перепада влажности является причиной перемещения влаги по направлению от центральных слоев к периферийным.

В результате проведенных исследований достигнуты следующие результаты:

- определен характер изменения влажности поверхностных и внутренних слоев древесины во времени при различных условиях обрабатывающей среды;

- определен характер зависимости перепада влажности от условий обрабатывающей среды во времени;

- произведена оценка влияния начальной влажности древесины, толщины образца, степени насыщенности и температуры обрабатывающей среды на продолжительность прогрева и на характер изменения влажности внутренних и поверхностных слоев образца во времени.

Полученные экспериментальные данные могут быть использованы при разработке ресурсосберегающих режимов начального прогрева древесины сосны.

\section{Список литературы}

1. Руководящие технические материалы по технологии камерной сушки древесины. Архангельск: ЦНИИМОД, 1985. 92 с.

2. Фридман И. Н. Деревообработка. Практическое руководство. СПб.: Профикс, 2003. 543 с.

3. Кречетов И. В. Сушка и защита древесины. М.: Лесная пром-сть, 1987. 324 с.

4. Кречетов И. В. Сушка древесины. М.: Лесная пром-сть, 1980. 432 с.

5. Рудак О. Г., Снопков В. Б. Исследование начального прогрева древесины без дополнительного увлажнения обрабатывающей среды // Труды БГТУ. 2011. № 2: Лесная и деревообраб. пром-сть. C. 212-214.

6. Рудак О. Г, Гуз Ю. А., Снопков В. Б. Исследование напряженно-деформированного состояния древесины при прогреве в ненасыщенной среде // Энерго- и материалосберегающие экологически чистые технологии: тез. докл. IX Междунар. науч.-техн. конф. Гродно: ГрГУ, 2011. С. 30-31.

7. Рудак О. Г. Изменение влажности пиломатериалов по толщине при прогреве в ненасыщенной среде // Труды БГТУ. 2012. № 2: Лесная и деревообраб. пром-сть. С. 165-167.

8. Лыков А. В. Тепло- и массообмен в процессах сушки. М.: ГосЭнергоИздат, 1956. 463 с.

9. Шубин Г. С. О коэффициентах переноса тепла и влаги в древесине // Деревообраб. пром-сть. 1989. № 8. С. 10-13. 
10. Чудинов Б. С. Теория тепловой обработки древесины. М.: Наука, 1968. 255 с.

11. Серговский П. С., Расев А. И. Гидротермическая обработка и консервирование древесины: М.: Лесная пром-сть, 1987. 360 с.

12. Лыков А. В. Тепло- и массообмен в процессах сушки. М.: Госэнергоиздат, 1956. 464 с.

13. Шубин Г. С. Сушка и тепловая обработка древесины. М.: Лесная пром-сть, 1990. 335 с.

\section{References}

1. Rykovodyashchiye tekhnicheskiye materialy po tekhnologii kamernoy sushki drewesiny [Guiding technical materials on the technology of chamber drying of wood]. Archangelsk, TsNIIMOD Publ., 1985. $92 \mathrm{p}$.

2. Fridman I. N. Derevoobrabotka. Prakticheskoye rykovodstvo [Woodworking. A practical guide]. St. Petersbyrg, Profiks Publ., 2003. 543 p.

3. Krechetov I. V. Sushka i zashchita drevesiny [Drying and wood protection]. Moscow, Lesnaya promyshlennost' Publ., 1987. 324 p.

4. Krechetov I. V. Sushka drevesiny [Drying of wood]. Moscow, Lesnaya promyshlennost' Publ., 1980. $432 \mathrm{p}$.

5. Rudak O. G., Snopkov V. B. Study of the initial heating of wood without additional moistening of the processing environment. Trudy BGTU [Proceedings of BSTU], 2011, no. 2: Forest and Woodworking Industry, pp. 212-214 (In Russian).

6. Rudak O. G., Guz Yu. A., Snopkov V. B. Study of the stress-strain state of wood when heated in an unsaturated environment Energo- $i$ materialosberegayushchiye ekologicheski chistyye tekhnologii: tez. dokl. IX Mezhdunar. nauch.-tekhn. konf. [Energy- and material-saving environmental friendly technologies: abstract of the IX International Scientific and Technical Conference]. Grodno, 2011, pp. 30-31 (In Russian).

7. Rudak O. G. Change in the moisture content of lumber by thickness when heated in an unsaturated environment. Trudy BGTU [Proceedings of BSTU], 2012, no. 2: Forest and Woodworking Industry, pp. 165-167 (In Russian).

8. Lykov A. V. Teplo- i massoobmen v protsessakh sushki [Heat and mass transfer in drying processes]. Moscow, GosEnergolzdat Publ., 1956. 463 p.

9. Shubin G. S. On the coefficients of heat and moisture transfer in wood. Derevoobrabatyvayushchaya promyshlennost' [Woodworking industry], 1989, no. 8, pp. 10-13 (In Russian).

10. Chudinov B. S. Teoriya teplovoy obrabotki drevesiny [Theory of wood heat treatment]. Moscow, Nauka Publ., 1968. 255 p.

11. Sergovsky P. S., Rasev A. I. Gidrotermicheskaya obrabotka i konservirovaniye drevesiny [Hydrothermal processing and preservation of wood]. Moscow, Lesnaya promyshlennost' Publ., 1987. $360 \mathrm{p}$.

12. Lykov A. V. Teplo- $i$ massoobmen v protsessakh sushki [Methods of determining thermal conductivity and thermal conductivity]. Moscow, Gosenergoizdat Publ., 1973. 413 p.

13. Shubin G. S. Sushka i teplovaya obrabotka drevesiny [Drying and heat treatment of wood]. Moscow, Lesnaya promyshlennost' Publ., 1990. 335 p.

\section{Информация об авторах}

Рудак Оксана Геннадьевна - магистр технических наук, старший преподаватель кафедры технологии и дизайна изделий из древесины. Белорусский государственный технологический университет (220006, г. Минск, ул. Свердлова, 13а, Республика Беларусь). E-mail: oksrudak@mail.ru

Короб Анна Юрьевна - инженер кафедры технологии деревообрабатывающих производств. Белорусский государственный технологический университет (220006, г. Минск, ул. Свердлова, 13а, Республика Беларусь). E-mail: korob_98@mail.ru

\section{Information about the authors}

Rudak Oksana Gennadievna - Master of Engineering, Senior Lecturer, the Department of Technology and Design of Wooden Articles. Belarusian State Technological University (13a, Sverdlova str., Minsk, 220006, Republic of Belarus). E-mail: oksrudak@mail.ru

Korob Anna Yurievna - Engineer, the Department of Woodworking Technology. Belarusian State Technological University (13a, Sverdlova str., Minsk, 220006, Republic of Belarus). E-mail: korob_98@mail.ru. 

